Territorios 34 / Bogotá, 2016, pp. 17-34

ISSN: 0123-8418

ISSNe: 2215-7484

La fase actual del capitalismo y la urbanización en América Latina (I)

\title{
Los territorios latinoamericanos en la mundialización del capital
}

The Latin American Territories in the Mondialization of Capital

Os territórios latino-americanos na mundialização do capital

\author{
Lisett Márquez López* \\ Emilio Pradilla Cobos**
}

Recibido: 30 de junio de 2015

Aprobado: 23 de noviembre de 2015

Doi: dx.doi.org/10.12804/territ34.2016.01

Para citar este artículo:

Márquez L., L. \& Pradilla C., E. (2016). Los territorios latinoamericanos en la mundialización del capital. Territorios, 34, 17-34. Doi: dx.doi.org/10.12804/territ34.2016.01

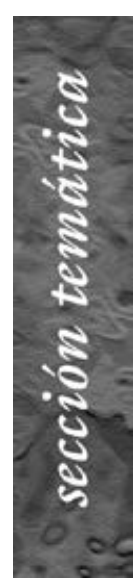

* Licenciada en Diseño de los Asentamientos Humanos, Universidad Autónoma Metropolitana, Xochimilco, México; Maestra en Estudios Regionales, Instituto de Investigaciones José María Luis Mora, México; Doctora en Urbanismo, Universidad Nacional Autónoma de México; Estancia posdoctoral, Universidad Autónoma Metropolitana, Xochimilco, México. Profesora Invitada en la División de Ciencias Sociales, Departamento de Relaciones Sociales, Universidad Autónoma $\mathrm{Me}$ tropolitana, Xochimilco, México. Correo electrónico lismarq@hotmail.com

** Arquitecto, Universidad Nacional de Colombia; Tercer Ciclo en Técnicas Superiores del Desarrollo IEDES, Universidad de París, $\Rightarrow$ 
Palabras clave

Mundialización capitalista, desarrollo desigual y combinado,

América Latina, rasgos diferenciales, teorización particular.

Keywords

Capitalist's mondialization, unequal and combined development, Latin America, distinctive features, particularly theorizing.

Palavras-chave

Mundialização capitalista, desenvolvimento desigual e combinado, América Latina, rasgos diferenciais, teorização particular.

\section{territarias 34}

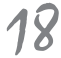

\section{RESUMEN}

Desde su conquista y colonización por parte de España y Portugal, América Latina ha estado articulada, como polo dominado, al proceso de acumulación originaria de capital en Europa, a las sucesivas fases de la mundialización del capital y a la hegemonía del imperialismo. Esta situación de subordinación y el desarrollo desigual y combinado del capitalismo han dado lugar en el subcontinente a particularidades tanto en su conformación socio-económica como en la estructuración territorial y urbana. El patrón neoliberal de acumulación vigente ha profundizado estos rasgos diferenciales. Por lo tanto, las teorizaciones urbanas concretas elaboradas para los polos hegemónicos del capitalismo actual son inadecuadas para analizar las realidades latinoamericanas.

\section{ABSTRACT}

Since its conquest and colonization by Spain and Portugal, Latin America has been articulated as a dominated pole to the process of primitive accumulation of capital in Europe, to the successive phases of the capital's mondialization, and to the imperialism hegemony. This subordinate position and the uneven and combined development of capitalism have resulted in particularities both in the socioeconomic formation and terrritorial and urban structure of the subcontinent. The current neoliberal accumulation pattern has deepened these distinguishing features. Therefore, the specific urban theories developed for the hegemonic poles of capitalism today are inadequate to analyze Latin American realities.

\section{RESUMO}

Desde a sua conquista e colonização pela Espanha e Portugal, a América Latina tem estado articulada, como polo dominado, ao processo de acumulação originária de capital na Europa, às sucessivas fases da mundialização do capital, e à hegemonia do imperialismo. Esta situação de subordinação e o desenvolvimento desigual e combinado do capitalismo têm dado lugar no subcontinente a particularidades tanto em sua conformação socioeconômica como na estruturação territorial e urbana. O patrão neoliberal de acumulação vigente tem aprofundado estes rasgos diferenciais. Portanto, as teorizações urbanas concretas elaboradas para os polos hegemônicos do capitalismo atual são inadequadas para analisar as realidades latino-americanas. 


\section{Introducción}

Algunas de las teorizaciones más populares entre los investigadores urbanos en América Latina postulan la actual emergencia de un nuevo modo de producción, el informacional (Castells, 1995; Castells \& Hall, 1994; Castells, 1998); por su parte, los seguidores de la teoría de la regulación sostienen una periodización de la historia económica y social en términos de metáforas individualistas de fases del desarrollo tecnológico - fordismo, posfordismo(Leborgne \& Lipietz, 1987; Leborgne \& Lipietz, 1994). Ambas formulaciones, que se superponen o intersectan en diferentes planteamientos, sobre todo en el papel determinante de las nuevas tecnologías - en particular la informática y las telecomunicaciones- en el desarrollo económico y social, tienen derivaciones hacia el campo del análisis urbano. En anteriores trabajos se han formulado las críticas a estos planteamientos (Pradilla, 2009; Pradilla, 2013b). Basta ahora señalar que el determinismo tecnológico que comparten conduce, independientemente de la voluntad de los autores, por diferente vía, al ocultamiento de las relaciones de explotación y de hegemonía internacional en el capitalismo actual.

La 'globalización', vocablo de origen neoliberal (Chesnais, 1994; Guillén, 2005) que pretende designar la actual etapa del desarrollo histórico, además de sus imprecisiones históricas, se ha convertido en un mito ideológico unificador de distintas y, aparentemente, opuestas posturas teóricas y políticas, que trata, arbitrariamente, de homogeneizar al mundo y sus territorios, y de explicar todos los procesos económico-sociales y territoriales, ignorando u ocultando la ley del desarrollo desigual y combinado $^{1}$ de las formaciones sociales capitalistas (Pradilla, 2009).

Se considera más correcto teóricamente hablar de la manifestación actual de las desiguales formas económicas, políticas y culturales de dominio del imperialismo, en el patrón neoliberal de acumulación de capital, como fase del proceso multisecular de la mundialización del capital.

La clave para desentrañar esta oposición teórica se encuentra en el carácter desigual y combinado del desarrollo de todas las formas sociales en la historia y, en particular, en el capitalismo, cuando se manifiesta en el tiempo, en los distintos territorios y en la extensión y la profundidad de los procesos de subsunción real o formal al capital y de mercantilización de todas las cosas (Wallerstein, 1988).

\section{El desarrollo histórico de América Latina}

El desarrollo histórico de lo que conocemos hoy como América Latina desde antes de su descubrimiento y conquista por los españoles y portugueses ha sido desigual y combinado (Castillo \& Pradilla, 2015), tanto entre sus distintas formaciones sociales como, sobre todo, con los países hegemónicos, imperialistas por los que ha sido dominada.

En el siglo XV, cuando en Europa estaba ya en curso la transición del feudalismo
Francia; Maestro en Arquitectura, Universidad $\mathrm{Na}$ cional Autónoma de México; Doctor en Urbanismo, Universidad Nacional Autónoma de México. Profesor Titular Cen la División de Cienciasy Artes para el Diseño, Departamento de Teoría y Análisis, Universidad Autónoma Metropolitana, Xochimilco, México. Correo electrónico:epradillacrm@ hotmail.com

1 "Las leyes de la historia no tienen nada de común con el esquematismo pedantesco. El desarrollo desigual que es la ley más general del proceso histórico, no se nos revela, en parte alguna, con la evidencia y la complejidad con que lo patentiza el destino de los paises atrasados. Azotados por el látigo de las necesidades materiales, los paises atrasados se ven obligados a avanzar a saltos. De esta ley universal del desarrollo desigual se deriva otra que, a falta de nombre más adecuado, calificaremos de ley del desarrollo combinado, aludiendo a la aproximación de las distintas etapas del camino y a la combinación de distintas fases, a la amalgama de formas arcaicas y modernas" (Trotsky, 1972).

\section{territarias 34}

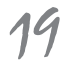


${ }^{2}$ Este texto fue reeditado como capitulo I, segunda parte, en Pradilla, 2009.

${ }^{3}$ Nos apoyamos en estos dos textos a lo largo de todo el apartado hasta la imposición del patrón neoliberal de acumulación en los años ochenta.

territarias 34 20 al capitalismo, con la fase de la acumulación originaria de capital (Marx, 1975), en nuestro continente coexistían tres formas distintas de organización social, desigualmente desarrolladas: tribus nómadas bárbaras, comunidades aldeanas primitivas y comunidades asiáticas (americanas) más desarrolladas (incas en Perú, aztecas y mayas en México y Guatemala), aisladas entre sí o en conflicto en sus bordes territoriales (Pradilla, 1993) ${ }^{2}$. Estas formas sociales opusieron grados muy distintos de rechazo armado o pasivo a la conquista ibérica, que significaron su destrucción parcial o total, o su menor o mayor integración por sometimiento en la sociedad colonial.

A diferencia de Europa, a su arribo, los conquistadores encontraron un inmenso territorio en gran parte cubierto por la selva, en parte poco poblado y otras áreas densamente habitadas. Su ocupación territorial fue desigual y se prolongó en el tiempo al menos hasta mediados del siglo $\mathrm{xx}$, aunque aún existen áreas poco conocidas.

Lo que surgió en el subcontinente luego de la conquista, en la colonia, en correspondencia con la transición europea pero con notorias especificidades regionales, fue una organización socio-económica transicional que combinaba desigualmente formas sociales heredadas del pasado precolombino, feudalizadas con fuertes rasgos semiserviles, la esclavitud reimplantada para paliar el desastre demográfico indígena, pequeña producción agraria parcelaria y formas campesinas libres, artesanía y un embrionario intercambio mercantil en manos de los ibéricos (Pradilla, 1993;
Kalmanóvitz, 1983)³. Como señala Marx, las colonias latinoamericanas se articularon al proceso de la acumulación originaria de capital en Europa mediante el despojo de las tierras a las comunidades indígenas en beneficio de las coronas de España y Portugal y de sus colonos concesionarios; el arrebato del oro y la plata atesorados por los indígenas y luego mediante la explotación esclavista de la minería (Vilar, 1972); las ganancias del tráfico de esclavos desde África por las Compañías de Indias; la piratería inglesa, francesa y holandesa que robaba metales preciosos y mercancías a los colonizadores; $\mathrm{y}$ el intercambio desigual de las mercancías europeas en el continente americano, en el marco del monopolio ibérico del comercio; vías que alimentaron la génesis del capital en Europa, sobre todo en Inglaterra.

Las luchas que condujeron a la Independencia de la mayoría de los países latinoamericanos se desataron cuando ya las revoluciones burguesas en Europa, sobre todo la inglesa y la francesa, habían derrotado a las monarquías absolutas para imponer formas burguesas de Estado, y la primera revolución industrial -incluyendo la tecnológica-, estaba en su apogeo (Mandel, 1986), transformando su territorio debido al proceso de urbanización que la acompañó (Benévolo, 1979; Ragon, 1979). En estas luchas independentistas cumplieron un papel importante tanto la ideología burguesa revolucionaria europea, como el interés de los comerciantes criollos de librarse de las ataduras impuestas por el monopolio colonial del comercio.

Lisett MÁrquez López, Emilio Pradilla Cobos 
Las repúblicas independientes resultantes de la fragmentación de la colonia española liquidaron la institución de la esclavitud ya en decadencia y abrieron el camino a una acumulación originaria de capital local, basada en el despojo de las tierras a los colonos que asumieron posiciones proclives a las monarquías europeas, el cual continuó con la liquidación del resguardo indígena y las desamortizaciones de los bienes de manos muertas - tierras rurales y urbanas de la iglesia y tierras comunes de las comunidades indígenas - cuya venta a propietarios privados dio lugar a una re-concentración de la propiedad territorial, al crecimiento del campesinado parcelario y la formación de una masa de sobrepoblación relativa.

Durante el resto del siglo XIX e inicios del siglo $\mathrm{Xx}$, en el campo latinoamericano dominó el sistema de la hacienda de plantación o la basada en la aparcería, donde imperaban relaciones sociales semiserviles anudadas mediante la coerción y la renta del suelo cobrada en especie o trabajo (Kalmanóvitz, 1983), en el que estuvo presente la empresa agraria trasnacional; a su vez había regiones donde dominaba la pequeña propiedad campesina libre que, en algunos casos, desarrolló relaciones embrionarias de tipo mercantil. En la medida que se definían los productos agropecuarios de exportación, en los diferentes países, la hacienda se articulaba a la relación con el mercado mundial, comúnmente acentuando la opresión servil (Pradilla, 1993). Al mismo tiempo, en las ciudades más grandes, sobre todo las capitales, se desarrollaba el sector comercial ligado a la exportación agropecuaria y la importación de bienes manufacturados de lujo, subordinada a la relación con los países europeos ya industrializados.

La fase descendente de la acumulación de capital y de decadencia del librecambismo en Europa - 1873 a 1893 - (Mandel, 1986), trajo consigo tres procesos cruciales en América Latina: la llegada de capitales que no podían valorizarse allí por la sobreacumulación, hacia la inversión en la minería y los transportes - marítimos, fluviales y ferroviarios-, cuyo desarrollo significó procesos de colonización e integración territorial y urbanización en nuestra región; el arribo (desigual según los países) de una masa de migrantes europeos a América del Sur y del Norte en busca de trabajo; y un proceso incipiente de industrialización en los grandes países del subcontinente (Brasil, Argentina y México) en los cuales estuvo presente el capital extranjero (Kalmanóvitz, 1982; Pradilla, 1993). Las luchas políticas internas, los golpes militares y las intervenciones políticas y militares imperialistas acompañaron esta fase y todo el primer medio siglo $\mathrm{xx}$, con notoria agudeza en México y Centroamérica. Así, mientras el capital industrial y bancario se fundían en el financiero formando la base económica del imperialismo capitalista europeo, se desplazaba hacia América Latina, y se le hacía sentir a esta su peso político y militar, y el naciente poderío estadounidense intervenía en México y Centroamérica, nuestra región continuaba anclada en un sistema agrario semiservil reforzado por el auge de las exportaciones agropecuarias, en el capi- territarias 34 
talismo mercantil urbano y en un limitado desarrollo de los transportes modernos y la industria capitalista.

En América Latina, en la segunda posguerra mundial, la industrialización en extensión tuvo tres características básicas: fue desigual, tardía y trasnacionalizada. No incluyó a todos los países, pues básicamente se industrializaron Argentina, Brasil, México y, en menor medida, Perú, Colombia y Chile, mientras que los países pequeños como los centroamericanos, Paraguay, Bolivia y Ecuador tuvieron que esperar aún varias décadas para que ella iniciara; y en todos los casos, el resultado fue muy desigual. Su inicio ocurrió tardíamente, 160 años después del comienzo de la revolución industrial en Europa, cuando allí y en Estados Unidos el grado de concentración y centralización monopólica del capital era muy alto, cuando se había elevado considerablemente la composición orgánica de capital y el avance técnico implicaba ya la necesidad de una pequeña cantidad de fuerza laboral relativa a la masa de producción. Puesto que la industria en Latinoamérica no desarrolló significativamente su sector de producción de medios de producción, tenía que importarlos mayoritariamente de Europa y Estados Unidos, dando lugar a un déficit estructural de la balanza comercial, pues la industrialización implicaba un incremento de la necesidad de divisas generadas por el sector agropecuario y minero, al cual era incapaz de responder, obligando al endeudamiento externo o a depender de la inversión extranjera directa territarias 34 22 proteccionismo generalizado en la región no se aplicó al capital extranjero, sino a la producción externa, lo que permitió que el capital trasnacional, bien recibido en razón del déficit estructural de la balanza comercial, estuviera presente, con un papel protagónico, en la industrialización latinoamericana, importando al país la composición técnica del capital imperante en los países y plantas matrices de origen (Fajnzylver \& Martínez, 1976).

El desarrollo industrial entre 1940 y 1980 impuso la penetración de las relaciones capitalistas de producción e intercambio en el campo latinoamericano, por la vía junker - gran terrateniente-, la más autoritaria y violenta, que desplazaba masivamente población del campo para concentrar la tierra mediante el despojo, dar lugar a un excedente de producción de materias primas para la industria y alimentos para el consumo urbano y enviar fuerza laboral a las ciudades para su proletarización (Pradilla, 1981; Pradilla, 2009) sin que esto significara la descomposición total de las formas pre-capitalistas rurales, que subsistieron en las peores tierras o las más alejadas de las ciudades, o donde los campesinos minifundistas o comunitarios no quisieron abandonar la tierra. Estas condiciones del desarrollo capitalista en el campo y en la industria produjeron una gigantesca sobrepoblación relativa latente o estancada, que ha caracterizado a la región desde entonces y que, transformada en ejercito industrial de reserva, junto con la debilidad del sindicalismo, controlado o reprimido, han mantenido estructuralmente

Lisett Márquez López, Emilio Pradilla Cobos 
niveles salariales muy bajos en la región (Castillo \& Pradilla, 2015).

Desde la conclusión de las independencias nacionales con respecto a los países colonizadores, los procesos de fragmentación y consolidación de los Estados Nacionales, la definición de la estructura de sus regímenes políticos (centralismo o federalismo), la resolución de las luchas agrarias y democrático-burguesas a favor de los terratenientes y la burguesía, la conducción del proceso de industrialización, el control del sindicalismo y hasta el paso del intervencionismo estatal al neoliberalismo han estado acompañados de guerras civiles, dictaduras militares y otros regímenes de excepción, violencia y represión interna e intervenciones políticas y/o militares del imperialismo europeo o norteamericano, causando sufrimiento y miseria a los sectores populares. En particular, las luchas defensivas del campesinado ante la violencia terrateniente, los movimientos democrático-burgueses y anti-dictatoriales, los movimientos guerrilleros a lo largo de casi todo el siglo Xx fueron enfrentados mediante dictaduras militares y la represión abierta. Estos procesos dan validez, también para América Latina, a la frase lapidaria de Marx (1975) "Si el dinero, como dice Augier, viene al mundo con manchas de sangre en una mejilla, el capital lo hace chorreando sangre y lodo por todos los poros, desde la cabeza hasta los pies" (p. 950).

En América Latina el tránsito, desigual en el tiempo según los países, del intervencionismo estatal al neoliberalismo como patrón de acumulación de capital fue vehiculado por la combinación de vectores constituidos por las políticas neoliberales militantes de los estados de la triada hegemónica mundial; los organismos financieros multinacionales controlados por los países dominantes (FMI y Banco Mundial); las empresas trasnacionales instaladas en la región y los gobernantes conservadores latinoamericanos ${ }^{4}$. Desde mediados de los setenta, empezando por la dictadura de Pinochet en Chile, y más o menos rápidamente luego de la crisis de 1982, se fueron implantando la apertura de las fronteras y la liberación de los flujos internacionales de mercancías y capitales; las facilidades para el ingreso de inversión extranjera a la agricultura, la minería extractiva, la industria, el comercio, los servicios, el sector inmobiliario y sobre todo el sector bancario y financiero; la privatización masiva de las empresas públicas; la desnacionalización de empresas privadas por venta o asociación; la flexibilización de la legislación laboral para modificar las condiciones de trabajo y facilitar la reducción del salario real de los trabajadores; la desregulación de las relaciones económicas; la aceleración del cambio tecnológico en la producción, el intercambio, los servicios y el sector financiero; y la mercantilización y financiarización de la vida social (Pradilla, 2013a). Rápidamente, los Estados Nacionales transitaron del papel de interventores al de facilitadores de la acción del capital privado, particularmente el trasnacional, y mediatizadores del conflicto social en beneficio del capital (Chesnais, 1994; Pradilla, 2009; Guillén, 2005).
${ }^{4}$ Recordemos que a inicios de los añosochenta, en la región, dominaban las dictaduras militares o gobiernos civiles abiertamente conservadores. 
${ }^{5}$ Nos referimos a la actividad de ensamblaje intermedio o final de insumosy productos, mediante subcontratación, generalizada en la frontera México-Estados Unidos, o en sectores como el automotriz, electrónico y el de electrodomésticos.

${ }^{6}$ El PIB total de América Latina y el Caribe creció en promedio anual: $5,1 \%$ entre 1950-1960; 5,5\% entre 1960-1970; 6,3\% entre 1970-1980; 1,2\% entre 1980-1990; 3,2\% entre 1990-2000; 3,6\% entre 2000-2008; y 4,1\% entre 1950-2008 (ONU HABITAT, 2010, p. 196)

\section{tersitarias 34}

El resultado de la aplicación en nuestra región de esta nueva versión conservadora del viejo librecambismo se puede sintetizar con un conjunto de rasgos: multiplicación de las formas de despojo de los pequeños productores agropecuarios, mineros, industriales, comerciales y de servicios; desindustrialización relativa prematura de los países más industrializados y de sus metrópolis (Salama, 2012; Márquez \& Pradilla, 2008) y maquiladorización ${ }^{5}$ de sectores productivos enteros en función de la reorganización territorial internacional de la producción; trasnacionalización creciente de la economía latinoamericana en su conjunto; crecimiento de la sobrepoblación relativa y multiplicación de sus formas de subsistencia, incluida la violencia (Castillo \& Pradilla, 2015); y pérdida de dinamismo de las economías latinoamericanas ${ }^{6}$. Entre los estertores de las crisis financieras - eufemísticamente denominados efectos (vodka, dragón, tequila, tango, samba)—, y de las recesiones recurrentes - 1982, 1990, 1995, 2002 y 2009- (Pradilla, 2009, pp. 312-316), el capital financiero trasnacional, que absorbió la mayor parte de los bancos nacionales de la región, asumió la hegemonía plena sobre las demás fracciones del capital en los países de la región, incluido el inmobiliario.

Las formaciones económico-sociales latinoamericanas aparecen hoy como una compleja combinación de formas heterogéneas desigualmente desarrolladas que incluyen: en el campo, comunidades indígenas pauperizadas y excluidas (México, Guatemala, Colombia, Ecuador, Bolivia,
Perú, Brasil, Chile), campesinos pobres minifundistas pre-capitalistas, pequeños productores capitalistas atrasados, medianas y grandes haciendas y agro-industrias modernas; en la ciudad: las mil formas precapitalistas de subsistencia de la sobrepoblación relativa en la artesanía, el comercio y los servicios (Castillo \& Pradilla, 2015), medianas y grandes empresas capitalistas con diferentes grados de productividad en todas las ramas de actividad, hasta las filiales de trasnacionales mineras, industriales, comerciales, de servicios, bancarias y financieras. Todo este universo complejo y conflictivo está subsumido, integrado, formal o realmente al proceso de acumulación de capital dominado por el capital financiero trasnacional.

Como reacción política del profundo malestar social generado por el neoliberalismo salvaje, en la primera década del siglo XXI, y hasta ahora, han llegado al poder por la vía electoral, en países como Chile, Argentina, Brasil, Uruguay, Paraguay, Bolivia, Ecuador, Venezuela, Nicaragua o El Salvador, gobiernos que se autodefinen como progresistas, de izquierda y defensores de los intereses del sector popular, que son portadores de ideologías heterogéneas, algunos notoriamente socialdemócratas tradicionales, armados con un discurso más o menos contrario al neoliberalismo, que intentan aumentar la presencia del Estado sobre todo en el ámbito de las políticas sociales, pero que en realidad no logran revertir lo fundamental de las reformas neoliberales, ni compensar el peso del capital trasnacional, ni liberar a sus países de

Lisett Márquez López, Emilio Pradilla Cobos 
las redes del capital financiero mundial. Sin embargo, en su conjunto, los países latinoamericanos, con regímenes políticos muy desiguales, aún carecen de sólidas estructuras democrático-burguesas y los derechos ciudadanos son aún débiles e insuficientes. Ahí nos encontramos hoy día.

\section{Mundialización del capital e imperialismo}

Del breve recuento de las características básicas de las formaciones sociales latinoamericanas en diferentes etapas a lo largo de más de cinco siglos, se desprenden varios hechos. En primer lugar, la desigualdad del desarrollo de las distintas formas constitutivas de la totalidad económico-social en cada momento de la historia, en cada uno de sus fragmentos territoriales jurídicamente reconocidos, lo que lleva a que aparezca como un todo caleidoscópico, una combinación de formas heterogéneas y desigualmente desarrolladas. En segundo lugar, que en la región latinoamericana, cada uno de estos fragmentos, en cada momento histórico, presente particularidades, grados distintos de desarrollo, a pesar de la existencia de rasgos generales homólogos, lo que lleva a que la región se muestre como una totalidad de partes desigualmente desarrolladas. En tercer lugar, que el devenir de las formaciones sociales latinoamericanas no es igual ni simultáneo al curso seguido por los países que ocupaban en ese momento el papel de potencias dominantes y/o hegemónicas en lo político-militar o económico, aunque su camino sea marcado por estas. En cuarto lugar, que las formaciones sociales latinoamericanas han estado ubicadas en todos estos momentos históricos en el polo dominado de la relación, mediante la violencia militar y el despojo, la coerción política y económica ejercida por medio de las redes del intercambio de mercancías y/o capitales y del financiamiento-endeudamiento o el consenso heterónomo de las clases dominantes de los países dominados.

El proceso histórico latinoamericano ha estado inserto en las diferentes fases de la mundialización del capital, bajo la hegemonía económica y político-militar de los diferentes imperialismos. Se entiende por mundialización del capital como el proceso histórico, desigual en el tiempo y la intensidad, aún inacabado, de extensión territorial en el planeta y profundización social de las relaciones capitalistas de producción e intercambio mercantil y monetario. No se utiliza el concepto de globalización, por su origen neoliberal, su proclividad hacia los intereses de las trasnacionales (Chesnais, 1994; Guillén, 2005), su ambigüedad en términos de la naturaleza de clase y de dominio nacional de sus caracterizaciones, y su uso indistinto e indefinido por parte de actores intelectuales y políticos de todo el abanico ideológico. Guillén (2005) afirma que "Actualmente, la globalización puede ser captada a través de tres indicadores: el intercambio de mercancías con el exterior; la inversión extranjera directa; y los flujos internacionales de capital-dinero" (p. 32). Se cree que, guardadas las proporciones históricas, estos indicadores pueden ser utilizados en etapas anteriores 
del proceso histórico; también que el análisis debe completarse con la disección de los procesos políticos y culturales que viabilizan o imponen la generalización de las relaciones capitalistas en un momento determinado, lo que amplía el panorama hacia la relación entre mundialización e imperialismo.

Como afirman muchos, la mundialización del capital no inició en 1980 con el neoliberalismo; tiene más de cinco siglos de edad (Guillén, 2005; Pradilla, 2009), se inició a finales del siglo XV e inicios del XVI con la conquista y colonización de América por los europeos, la expansión territorial correspondiente, los movimientos masivos de población que trajo consigo, su papel en la formación de la economíamundo (Ferrer, 1996; Wallersteín, 1984) y la imposición de las formas de despojo que alimentaron la acumulación originaria de capital en Europa. A lo largo de más de tres siglos, la inserción de América Latina en la mundialización del capital estuvo mediada por el control colonial de las potencias imperiales europeas, España y Portugal.

Luego de las revoluciones políticas burguesas contra las monarquías absolutas y la primera revolución industrial y tecnológica europea (1780-1840), los nuevos países independientes de América Latina se subordinaron a la expansión comercial del capitalismo industrial de las potencias europeas, sobre todo Inglaterra y Francia, bajo la forma mercantil de la exportación de materias primas - en especial agropecuarias y mineras - y la importación de manufacturas, lo cual dio lugar a una etapa de profundización de la mercantilización en la región. A finales del siglo XIX, la formación del capital financiero a partir de la fusión del capital industrial y el bancario, como relación económica y como fracción de la clase capitalista, se combina con el colonialismo europeo en Asia y África, para dar lugar a una nueva etapa del imperialismo como forma e instrumento de la mundialización del capital. La presencia de capitales europeos y estadounidenses en la agricultura, la minería, los transportes y la banca vehicula la acción interna imperialista en América Latina, a la cual se suma la intervención política y militar que tiene a finales del siglo XIX y a lo largo de casi todo el Xx como actor al creciente imperialismo estadounidense.

El periodo de crisis del capitalismo entre 1914 y 1945 , caracterizado por las dos guerras inter-imperialistas, la Gran Depresión y el avance del socialismo real, (Mandel, 1986), significa un retroceso en la mundialización del capital, $\mathrm{y}$, contradictoriamente, para América Latina un auge del nacionalismo burgués, y la creación de las condiciones para la industrialización tardía mediante la sustitución de importaciones. La industrialización latinoamericana misma, cuya etapa de mayor auge ocurrió entre 1940 y 1980, significó una nueva fase ascendente de la mundialización capitalista, articulada con los países hegemónicos por la dependencia de los medios de producción importados de los países industrializados y por la presencia determinante de las trasnacionales europeas y, sobre todo, estadounidenses en el proceso.

Lisett Márquez López, Emilio Pradilla Cobos 
El periodo neoliberal, cuyas características se señalaron anteriormente, es de aceleración del proceso de mundialización capitalista en los diferentes países de la región, particularmente por la liberación de los flujos mundiales de mercancías y, sobre todo, capitales en el marco del "libre comercio" y la "libre iniciativa privada" convertidos en ideología hegemónica, la búsqueda angustiosa de inversión extranjera como motor del desarrollo y factor de competitividad de los países de la región, la trasnacionalización del capital bancariofinanciero, su coinversión en la fracción plenamente hegemónica del capital tanto local como internacionalmente y la creciente financiarización de la mercantilización de la vida cotidiana (Pradilla, 2013a). En esta etapa, el papel del capital financiero trasnacional, la multiplicación de las formas de despojo neocolonial en la región (en el sector agropecuario y la minería, el sector energético, la privatización de lo público, etcétera), la coerción económica utilizando sobre todo los mecanismos financieros y la extraeconómica — política y militarllevan a afirmar que nos encontramos en una nueva fase de mundialización imperialista del capital o, como afirma Harvey, de "nuevo imperialismo" (Harvey, 2007). Esta situación es modificada, solo muy parcialmente, por la emergencia de gobiernos progresistas o de izquierda en la región, que limitan su acción a un mayor intervencionismo estatal en la actividad económica, y una política social de mitigación de la pobreza general o de los sectores más vulnerables focalizados a la manera del Banco
Mundial, y a medidas de ampliación de la democracia.

En general, se puede caracterizar al proceso histórico latinoamericano como una sucesión de fases de inserción en la mundialización del capital, y de dominación por las sucesivas relaciones imperialistas, con su dialéctica no lineal.

\section{Las particularidades del proceso de urbanización}

La especificidad histórica del capitalismo en América Latina, y su particular inserción en el proceso histórico de mundialización imperialista del capital, se ha expresado también en las particularidades de su proceso de urbanización y de estructuración de las ciudades.

Europa tuvo su fase más intensa de urbanización en el siglo XIX, a partir de la primera revolución industrial y tecnológica (Benevolo 1979; Ragón, 1979); en América Latina y el Caribe, este proceso se inició siglo y medio más tarde, pero ha sido más intenso y rápido, saltando etapas, que en el viejo continente. Al iniciar el proceso de Industrialización, la población de América Latina y el Caribe habitaba mayoritariamente dispersa en el ámbito rural; en 1950, solo el $41,4 \%$ de la población latinoamericana y caribeña total estaba concentrada en pueblos y ciudades; en 1990, concluida la fase más intensa de urbanización, este porcentaje alcanzaba el 70,6\%; en 2010, llegaba al $79,4 \%$ y se estima que en el 2030 habrá llegado al menos al $84,5 \%$, superando el porcentaje de urbanización media mun- territorios 34 
dial y el de África, Asia y Europa (Pradilla, 2009; ONU HABITAT, 2010). Evidentemente, la situación es todavía desigual entre los distintos países de la región, siendo mayor el grado de urbanización en los países más industrializados, lo cual indica potenciales de urbanización todavía elevados en algunos de los que aún presentan índices bajos (Pradilla, 2009); esto lo indica la participación relativa de la migración rural en el crecimiento urbano que varía en el período 1990-2000 entre 24,3\% en Argentina - la menor-y $59,5 \%$ en Guatemala - la mayor- (ONU HABITAT, 2010).

Este acelerado proceso de urbanización ha dado lugar en la región a enormes centros urbanos, se estima que para el 2015 habrá en ella 58 ciudades de más de un millón de habitantes, 9 de las cuales sobrepasarían los 5 millones de habitantes, y dos de ellas, las zonas metropolitanas de São Paulo y México, rondarán los 20 millones de habitantes colocándose entre las cinco mayores del planeta (Pradilla, 2009). En torno a las nueve mega-ciudades se están formando enormes ciudades región que superan ampliamente la población de sus metrópolis centrales. En el 2000, siete de las cincuenta ciudades más grandes del mundo eran latinoamericanas. El gigantismo urbano se está convirtiendo en una de las características de la distribución territorial de la población de América Latina.

A diferencia de los países del capitalismo hegemónico, la forma dominante en la expansión urbana en América Latina, y de producción de la vivienda popular, ha sido históricamente la que combina la ocupa- ción irregular del suelo y la autoconstrucción de vivienda, debido a la imposibilidad de la mayoría de la población de acceder a una vivienda adecuada en el mercado privado o público. Se estima que la mayor parte de la superficie de las ciudades latinoamericanas ha sido producida mediante esta forma de construcción del habitat popular (Pradilla, 1982; Pradilla, 1987; Connolly, 2013). Según ONU HABITAT, en 2005, más de 134 millones de personas, un 30,8\% de la población urbana total de los países latinoamericanos (cinco veces más que en las "regiones desarrolladas"), vivía en barrios marginales (ONU HABITAT, 2010). En diversos países del subcontinente, el proceso de ocupación irregular de suelo se nutrió de la presencia de formas pre-capitalistas de propiedad territorial como las tierras $\mathrm{CO}^{-}$ munitarias indígenas sobrevivientes desde la colonia, o las tierras ejidales decretadas luego de la revolución mexicana de inicios del siglo $\mathrm{XX}$, las cuales han ido desapareciendo de las legislaciones nacionales (Pradilla, 1992).

Durante varias décadas, la respuesta estatal a esta forma de producción popular del habitat fue la combinación y/o alternancia de acciones estatales de represión-desalojo o de permisividad, aún de promoción pública de la autoconstrucción en terrenos regulares legalmente, según la ideología de los actores gubernamentales o su percepción de la inevitabilidad de las formas de solución de la necesidad de vivienda por parte de los sectores populares (Coulomb, 2013); pero las ocupaciones irregulares de terrenos han entrado en conflicto abierto

Lisett MÁrquez López, Emilio Pradilla Cobos 
con la ideología y la práctica neoliberal, en el marco de la escasez de terrenos disponibles, su valorización en las metrópolis, y el discurso ambientalista aplicado unilateralmente, por lo que la permisividad estatal ha tendido a desaparecer, aunque no la práctica de subsistencia de la ocupación irregular y la autoconstrucción en la medida que la mayoría de la población no puede acceder ni siquiera a los programas de vivienda de interés social articulados entre los gobiernos y el capital inmobiliario. Otra respuesta de los pobres ha sido la densificación de las viejas áreas populares mediante saturación interior o la verticalización de las construcciones, ambas al margen de la legislación urbanística (Abramo, 2012). Tanto en las viejas barriadas, como en las periferias populares, ha penetrado la mercantilización de lo urbano, con la existencia de mercados informales de suelo y vivienda en venta o renta, subsumidos crecientemente al capital (Abramo, 2011; Abramo, 2012; Eibenschutz \& Benlliure, 2009).

Las últimas tres décadas han sido el escenario de un proceso de intensificación de la presencia y actividades del capital inmobiliario-financiero nacional-trasnacional en las grandes ciudades latinoamericanas, en operaciones puntuales o en mega-proyectos de renovación urbana en las áreas centrales (torres y complejos de usos mixtos, clubes privados, centros comerciales), cuyos efectos principales son el desplazamiento de la vivienda de diferentes sectores sociales por cambio de uso del suelo y los inmuebles (la terciarización), la sustitución de vivienda de sectores de bajos ingresos por la de sectores de ingresos medios y altos, y el incremento acelerado de las rentas del suelo con sus efectos de segregación social y/o expulsión. El capital inmobiliario-financiero nacional-trasnacional también ha invadido el sector de vivienda de interés social en la periferia, produciendo enormes ciudades dormitorio de viviendas minúsculas, de baja calidad, alejadas de la ciudad integrada y con pésima accesibilidad (Pradilla, 2010b, 2013a y 2014). Casi sin excepciones, este proceso ha llevado a la subordinación de las políticas urbanas a los intereses del capital inmobiliario-financiero, por razones de prestigio (la modernización), de competitividad urbana (atracción de capitales sobre todo extranjeros), o porque la desindustrialización de las metrópolis ha dejado como único motor de la creación de empleo a la industria de la construcción.

La desindustrialización relativa temprana de los países latinoamericanos antes señalada, ha tenido un escenario paradigmático en las grandes ciudades industrializadas en el período de la sustitución de importaciones; a ello han contribuido múltiples factores endógenos y exógenos; en el ámbito interno, las deseconomías de aglomeración, la valorización de los terrenos industriales al interior de la estructura urbana, las presiones por el suelo del capital inmobiliario, cuestiones ambientales simplistamente resueltas y políticas modernizantes anti-industriales de los gobiernos locales; en el ámbito externo, las políticas nacionales de libre mercado, la desigual competencia de los productos de la pequeña y mediana industria local con los importados, territarias 34 
la ausencia de políticas públicas de industrialización y la relocalización derivada de la reestructuración trasnacional de la estructura industrial. El resultado ha sido la pérdida relativa de dinamismo de las economías metropolitanas y la paulatina desaparición del sector más dinámico de la generación de empleo urbano (Pradilla \& Márquez, 2005; Márquez \& Pradilla, 2008; Pradilla, Moreno \& Márquez, 2012).

El resultado más notorio de la desindustrialización de las metrópolis ha sido la magnitud excesiva de la sobrepoblación relativa en las ciudades - la llamada informalidad-, cuyas actividades de subsistencia están ubicadas mayoritariamente en el sector terciario, lo cual lleva a una terciarización espuria. ONU HABIRAT señala que, alrededor del 2005, la informalidad en las áreas urbanas de países latinoamericanos seleccionados variaba entre 24\% (Argentina) y $51 \%$ (Bolivia) de la población económicamente activa (OINU HABITAT, 2010), datos que parecen subvaluados y que seguramente se elevaron a partir de la recesión de 2009. La presencia de las actividades de subsistencia de la sobrepoblación relativa en las calles de las ciudades latinoamericanas es innegable y se ha convertido en uno de sus rasgos específicos, característicos, que las diferencia de las ciudades en el capitalismo hegemónico.

Los reducidos ingresos tanto de la sobrepoblación relativa, como en general de los trabajadores asalariados, son factores, entre otros, del pauperismo que afectaba en 1970 al $62 \%$ de la población urbana de $\mathbf{5 9 \%}$, sin disminución significativa a lo largo del período neoliberal (ONU HABITAT, 2010). Otro de los factores explicativos del empobrecimiento de la población latinoamericana es el reducido ingreso per cápita promedio: US\$ 4356 anuales en el año 2005, variando entre US\$ 843 en Nicaragua y US\$ 8131 en Argentina (ONU HABITAT, 2010), en una región caracterizada por enormes disparidades en la distribución del ingreso: a mediados de la década del 2000, el $10 \%$ más rico de la población obtenía entre el 30,44\% del ingreso total en Venezuela y el $49,09 \%$ en Colombia, mientras que el $10 \%$ más pobre recibía entre el $0,39 \%$ en Bolivia y el $1,83 \%$ en Uruguay (ONU HABITAT, 2010).

En muchas ciudades de la región, la violencia está presente en las calles y barrios, alimentada por la superpoblación relativa que se lumpeniza para sobrevivir o por la coerción de la burguesía mafiosa que acumula masivamente capital en los intersticios y zonas oscuras del capitalismo a la manera neoliberal, en actividades como la delincuencia organizada, el narcotráfico, el contrabando de armas y otras mercancías, la trata de personas, el secuestro, etcétera. Las ciudades mexicanas son hoy el paradigma de esta violencia urbana irrefrenable, aunque no un caso aislado. El imaginario del miedo del que habla Carrión (2006), y la agorafobia que genera, explican en parte que los habitantes de las ciudades abandonen las calles y plazas públicas tradicionales y el transporte colectivo y se refugien en los centros y plazas comerciales privadas y el automóvil individual, que les ofrecen

Lisett Márquez López, Emilio Pradilla Cobos 
una seguridad imaginaria en los desplazamientos, la compra-venta y la recreación mercantilizada.

Las grandes ciudades latinoamericanas aparecen hoy como totalidades fragmentadas y socialmente segregadas en las que se combinan, conflictivamente, de un lado, las más contemporáneas obras arquitectónicourbanas de los más famosos despachos de arquitectura del mundo, con alta tecnología, dotados de todos los servicios urbanos de calidad, para el funcionamiento del capital y la vivienda de los capitalistas y sus administradores públicos y privados; $\mathrm{y}$, de otro lado, los más sórdidos conventillos centrales o degradados tugurios periféricos carentes de todo, donde habitan los asalariados peor pagados, la sobrepoblación relativa, el lumpen proletariado; son las dos caras de la misma moneda producida por el capitalismo neoliberal salvaje en Latinoamérica.

\section{Reflexión final: la realidad y la teoría}

Estas particularidades estructurales de nuestras ciudades, producto de los procesos específicos del desarrollo histórico de las formaciones sociales latinoamericanas, de su carácter desigual y de la heterogénea combinación de formas socio-territoriales resultante, hacen que nuestra realidad sea objetivamente distinta de la de las ciudades del capitalismo hegemónico. Unas y otras sociedades son capitalistas y acumulan capital según el patrón neoliberal, unas y otras ciudades son capitalistas y han sufrido notorias transformaciones a partir de la aplicación del neoliberalismo, pero sus procesos histórico-sociales han sido diferentes, ubicándose unas en el polo dominante, hegemónico, imperialista, de la mundialización del capital y otras en el polo dominado, explotado, de esa unidad.

La caracterización de ambos polos como capitalistas y la aplicación en ellos del patrón neoliberal de acumulación hacen válido en ambos casos el uso de las teorías generales que explican estos niveles de abstracción de la realidad. Pero las particularidades, las especificidades de las formaciones sociales latinoamericanas y sus ciudades resultantes conducen a la conclusión de que las teorías urbanas construidas en las sociedades capitalistas hegemónicas, europeas y estadounidenses, para explicar sus propias realidades y procesos urbanos son, en la mayoría de los casos, inadecuadas para explicar las realidades de las ciudades latinoamericanas, pues hasta aquello en que coinciden resulta diferente por ocurrir en conjuntos estructurales distintos (Pradilla, 2010a); es, por ejemplo, el caso de los mega-proyectos diseñados por arquitectos y urbanistas internacionales: su inserción en nuestra realidad modifica su propia y aparentemente atemporal y a-territorial realidad.

Esto lleva a la necesidad de construir una teorización propia para analizar los procesos territoriales-urbanos concretos en América Latina, partiendo de un uso creativo, desideologizado, sin dogmatismos estériles, de las teorías generales, para investigar nuestras propias realidades, las territarias 34 
particularidades, las totalidades concretas conflictivas resultantes, en la relación de unidad y contradicción con la situación de los polos hegemónicos, imperialistas, en el proceso de mundialización del capital, en sus componentes económicos, políticos, sociales, culturales, ambientales, etcétera.

\section{Referencias}

Abramo, P. (2011). O mercado de solo informal em favelas e a mobilidade residencial dos pobres nas grandes cidades brasileiras: notas para delimitar um objeto de estudo. En J. Natal (org.), Territorio e planejamento (pp. 217-236). Río de Janeiro: IPPUR, URFR, UFRJ y Letra Capital.

Abramo, P. (2012). La ciudad com-fusa: mercado y producción de la estructura urbana en las grandes metrópolis latinoamericanas, EURE, 38(114), 35-69.

Benevolo, L. (1979). Orígenes del urbanismo moderno. Madrid: H Blume.

Carrión, M. F., \& Núñez-Vega, J. (2006). La inseguridad en la ciudad: hacia una comprensión de la producción social del miedo, EURE, 32(97), 7-16.

Castells, M. (1995). La ciudad informacional. Madrid: Alianza.

Castells, M. (1998). La era de la información. Economía, sociedad y cultura. Madrid: Alianza.

Castells, M., \& Hall, P. (1994). Las tecnópolis del mundo. Madrid: Alianza.

Castillo de Herrera, M., \& Pradilla Cobos, E. (febrero, 2015). La informalidad como concepto ideológico y las formas de subsistencia de la sobrepoblación relativa en América Latina. Ponencia presentada en el II Seminario Internacional de la Red Latinoamericana de Investigadores sobre Teoría Urbana, Universidad Nacional de Colombia, Medellín, Colombia.

Chesnais, F. (1994). La mondialisatión du capital. Paris: Syros.

Connolly, P. (2013). La ciudad y el hábitat popular: paradigma latinoamericano. En B. Ramírez V. \& E. Pradilla C. (Comps.), Teorias sobre la ciudad en América Latina (pp. 505-562). México D.F.: Universidad Autónoma Metropolitana.

Coulomb Bosc, R. (2013). Las políticas de vivienda de los estados latinoamericanos. En B. Ramírez V. \& E. Pradilla C, Teorías sobre la ciudad en América Latina (pp. 563-616). México D.F.: Universidad Autónoma Metropolitana. Eibenschutz, H. R., \& Benlliure, B. P. (Coords.). (2009). Mercado formale informal de suelo. Análisis de ocho ciudades. México D.F.: Cámara de Diputados LX Legislatura, SEDESOL, Miguel Ángel Porrúa, UAM-X.

Fajnzylver, F., \& Martínez T. T. (1976). Las empresas trasnacionales. Expansión a nivel mundial y proyección en la industria mexicana. México D.F.: Fondo de Cultura Económica.

Ferrer, A. (1996). Historia de la globalización. Orígenes del orden económico mundial. Buenos Aires: Fondo de Cultura Económica. 
Guillén, R. H. (1984). Orígenes de la crisis en México. 1940-1982. México D.F.: Era.

Guillén, R. H. (2005). México frente a la mundialización neoliberal. México D.F.: Era.

Harvey, D. (2007). El nuevo imperialismo. Madrid: Akal.

Kalmanóvitz, S. (1983). El desarrollo tardio del capitalismo. Un enfoque crítico de la teoria de la dependencia. Bogotá: Universidad Nacional de Colombia y Siglo XXI.

Leborgne, D., \& Lipietz, A. (junio 1987). New technologies, new modes of regulation: some spatial implications. Ponencia presentada en International Conference Technology, restructuring and urbanregional development, Dubrovnik, Yugoslavia.

Leborgne, D., \& Lipietz, A. (1994). Flexibilidad ofensiva, flexibilidad defensiva. Dos estrategias sociales en la producción de los nuevos espacios económicos. En G. Benko \& A. Lipietz (Eds.), Las regiones que ganan (pp. 331-361). Valencia: Edicions Alfons El Magnanim.

Mandel, E. (1986). Las ondas largas del desarrollo capitalista. La interpretación marxista. Madrid: Siglo XXI.

Márquez, L. L., \& Pradilla C. E. (2008). Desindustrialización, terciarización y estructura metropolitana: un debate conceptual necesario. Cuadernos del CENDES, 69(25), 21-45.

Marx, K. (1975). El capital. México D.F.: Siglo XXI.
ONU HABITAT, (2010). Estado de las ciudades de América latina y el Caribe. Río de Janeiro: ONU HABITAT.

Pradilla, C. E. (1981). Desarrollo capitalista dependiente y proceso de urbanización en América Latina, Revista Interamericana de Planificación, XV(57), 73-99.

Pradilla, C. E. (1982). Autoconstrucción, explotación de la fuerza de trabajo y políticas del Estado en América Latina. En E. Pradilla C. (Comp.), Ensayos sobre el problema de la vivienda en América Latina (pp. 267-344). México D.F.: Universidad Autónoma Metropolitana, Xochimilco.

Pradilla, C. E. (1987). Capital, Estado y vivienda en América Latina. México D.F.: Editorial Fontamara.

Pradilla, C. E. (1989). Acumulación de capital y estructura territorial en América Latina. En M. Lungo (Comp.), Lo urbano: Teoría y métodos (pp. 31-67). San José: CSUCA, Editorial Universitaria Centroamericana.

Pradilla, C. E. (1992). La contrarreforma agraria y la cuestión territorial. En $\mathrm{Me}$ moria de la primera mesa redonda "Implicaciones de las reformas al Articulo 27 Constitucional y la nueva Ley Agraria, 12-14 febrero 1992, Coordinación General de Investigación y Estudios Avanzados, Universidad Autónoma del Estado de México, 1993, Toluca, México.

Pradilla, C. E. (1993). Acumulación de capital y estructura territorial en América Latina, Diseño y Sociedad, 3(3/93), 4-30. territarios 34

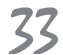


Pradilla, C. E. (2009). Los territorios del neoliberalismo en América Latina. México D.F.: Universidad Autónoma Metropolitana, Xochimilco y Miguel Ángel Porrúa.

Pradilla, C. E. (2010a). Teorías y políticas urbanas: ¿Libre mercado mundial o construcción regional?, Revista Brasileira de Estudos Urbanos e Regionáis, 12(2), 9-21.

Pradilla, C. E. (2010b). Mundialización neoliberal, cambios urbanos y políticas estatales en América Latina, Cadernos Métropole, 12(24), 507-533.

Pradilla, C. E. (2013a). Formas productivas, fracciones del capital y re-construcción urbana en América Latina, [inédito]. México D.F.: Universidad Autónoma Metropolitana, Xochimilco.

Pradilla C. E. (2013b). La economía y las formas urbanas en América Latina. En B. Ramírez V. B. \& E. Pradilla C. (Comps.), Teorias sobre la ciudad en América Latina (pp. 169-238). México D.F.: Universidad Autónoma Metropolitana.

Pradilla, C. E. (2014). La ciudad capitalista en el patrón neoliberal de acumulación en América Latina, Cadernos Métropole, 16(31), 37-60.

Pradilla, C. E. \& Márquez L. L. (2005). Estancamiento económico, desindus- trialización y terciarización informal en la Ciudad de México, 1980-2003, y potencial de cambio. En A. Torres R., H. Magalhaes T., J. Natal \& R. Piquet (Orgs.), Globalizacao e territorio. Ajustes periféricos (pp. 130-154). Río de Janeiro: Edicoes Arquímedes.

Pradilla, C. E., Moreno G. F., \& Márquez L. L. (2012). Cambios económicos y morfológicos en la Zona Metropolitana del Valle de México. En E. Duhau (Ed.), Ciudad de México: la construcción permanente de la metrópoli (pp. 46-91). Quito: OLACCHI.

Ragon, M. (1979). Historia mundial de la arquitectura y el urbanismo modernos, tomo l. Ideologías y pioneros 18001910. Barcelona: Destino.

Salama, P. (2012). Globalización comercial: desindustrialización prematura en América Latina e industrialización en Asia. Comercio Exterior, 62(6), 34-44.

Trotsky, L. (1972). Historia de la revolución rusa. México D.F.: Juan Pablos.

Vilar, P. (1972). Oro y moneda en la bistoria 1450-1920. Barcelona: Ariel.

Wallerstein, I. (1984). El moderno sistema mundial. II. El mercantilismo y la consolidación de la economía-mundo europea. 1600-1750. México D.F.: Siglo XXI.

Wallerstein, I. (1988). El capitalismo histórico. México D.F.: Siglo XXI. 